\title{
PENGATURAN LAMPU LALU LINTAS DI PERSIMPANGAN JALAN AHMAD YANI GIANT DENGAN APLIKASI PEWARNAAN TEORI GRAF
}

\author{
Erna Lus Diana $^{1}$, Wahyuni Suryaningtyas ${ }^{2}$, Endang Suprapti ${ }^{3}$ \\ Prodi Pendidikan Matematika FKIP UMSurabaya \\ ernalusdiana@gmail.com ${ }^{1}$,yuni.surya83@gmail.com²,end_sby@yahoo.com³
}

\begin{abstract}
Traffic jam is problems faced by many cities in Indonesia. The density of highways has caused the congestion. One solution is to use a traffic light. The existence of traffic lights help to curb road users, but in many cases the use of traffic lights is less than optimal. It is about the determination of flow which should be red or green and how long it takes for each stream. To overcome these problems, the coloring application used graph approach is as a point of scheduling problem resolution. The algorithm used is Welch-Powell. The case of a traffic light that occurs from several points in the city of Surabaya, one of which, is at the crossroads of Jalan Ahmad Yani Giant. Secondary data is from the Transportation Department of Surabaya including the results of the analysis of two-way road speeds using the Moving Car Observation of 2014, the average speed of vehicles in the city of Surabaya in 2010-2014, and the volume of vehicles on Jalan Ahmad Yani Surabaya. Congestion in Surabaya is caused by the increasing number or volume of vehicles in each year that is not balanced with the capacity of the road. Public awareness for the use of public transportation is also lacking. This is because the public transportation in the city of Surabaya has not fully meet the standards and many are not fit for use so that people prefer to use private transport. Congestion is also caused by the lack of regulation of traffic police at the point of congestion during rush hour.

From the above discussion, the result shows that the use of coloring application Graph Theory with Welch-Powell algorithm has improved the effectiveness of traffic lights which is seen from the total duration of the green and red light.
\end{abstract}

Keywords: Coloring Graf, Jalan Ahmad Yani, Traffic Lights, Welch-Powell, VB 6.0.

\section{PENDAHULUAN}

Matematika merupakan "Queen and Servant of Science” maksudnya adalah selain sebagai fondasi bagi ilmu pengetahuan juga sebagai pembantu bagi ilmu pengetahuan yang lain, khususnya dalam pengembangan ilmu pengetahuan tersebut. Matematika berfungsi untuk mengembangkan kemampuan komunikasi dengan menggunakan bilangan dan menggunakan ketajaman penalaran untuk menyelesaikan persoalan sehari-hari (Wilujeng, 2013:1-2). Matematika adalah bidang ilmu yang melatih penalaran supaya berpikir logis dan sistematis dalam menyelesaikan masalah dan membuat keputusan. Mempelajari matematika memerlukan cara tersendiri karena juga bersifat khas, yaitu abstrak, konsisten, hirarki, dan berpikir deduktif. (Itsnaini, 2013:1). 
Matematika diskrit atau diskret adalah cabang matematika yang membahas segala sesuatu yang bersifat diskrit. Diskrit disini artinya tidak saling berhubungan (lawan dari kontinu). Dengan demikian, hampir dapat dipastikan bahwa setiap bagian dari ilmu pengetahuan dan teknologi, baik ilmu murni maupun ilmu terapan akan memerlukan peran matematika sebagai ilmu bantunya. Salah satu cabang ilmu matematika yang diaplikasikan dalam kehidupan sehari-hari adalah teori graf.

Secara umum graf adalah suatu diagram yang memuat informasi tertentu, jika diinterpretasikan secara tepat. Dalam kehidupan sehari-hari graf digunakan untuk menggambarkan berbagai struktur yang ada. Tujuannya adalah sebagai visualisasi objek-objek agar lebih mudah dimengerti. Teori graf merupakan salah satu cabang dari matematika yang bermanfaat diberbagai bidang ilmu pengetahuan. Salah satu bagian dari teori graf adalah pewarnaan graf. Ada tiga macam pewarnaan graf, yaitu pewarnaan titik, pewarnaan sisi, dan pewarnaan bidang.

Penyelesaian masalah lampu lalu lintas dapat ditinjau dalam prespektif graf, yaitu dengan merepresentasikan persimpangan dalam bentuk graf. Titik pada graf menunjukkan arah perjalanan yang diperbolehkan dari jalan $\mathrm{X}$ menuju $\mathrm{Y}$, sedangkan sisi graf menunjukkan arah perjalanan yang tidak boleh dilakukan secara bersamaan. Selanjutnya menyelesaikannya dengan metode pewarnaan titik menggunakan algoritma Welch-Powell. Penyelesaian ini akan menghasilkan arusarus yang dapat berjalan secara bersamaa, selain itu juga diperoleh alternative durasi siklus baru.

Surabaya merupakan kota metropolitan kedua di Indonesia yang mempunyai banyak permasalahan, salah satunya adalah permasalahan lalu lintas. Hal ini dikarenakan bertambahnya jumlah kendaraan yang beroperasi tiap harinya dan menyebabkan kepadatan lalu lintas yang cukup tinggi di daerah-daerah tertentu di Surabaya khususnya jalan utama yang dilewati. Kepadatan di daerah tersebut menyebabkan penumpukan kendaraan pada simpang jalan. Sehingga sering ditemukan simpang-simpang yang kinerjanya kurang optimal.

Persimpangan merupakan jalinan jalan yang memiliki posisi penting dan kritis dalam mengatur lalu lintas (Rachmawati dan Novitasari, 2013:1). Suatu pengaturan dibutuhkan agar tidak terjadi penumpukan kendaraan pada persimpangan. Oleh karena itu, pengaturan sinyal yang optimal sangat diperlukan 


\section{Pengaturan Lampu Lalu Lintas Di Persimpangan Jalan Ahmad Yani Giant Dengan Aplikasi Pewarnaan Teori Graf}

untuk mengatur arus lalu lintas agar tidak terjadi permasalahan pada persimpanganpersimpangan di kota Surabaya.

Pembangunan frontage road diharapkan mampu meminimalisir gangguan yang terjadi pada arus lalu lintas karena konflik antar kendaraan yang melalui Jalan Ahmad Yani. Dalam mengatasi masalah kemacetan tersebut diperlukan adanya suatu solusi yang tepat. Solusi yang digunakan pada ruas Jalan Ahmad Yani adalah pembangunan frontage road disisi kiri jalan. Frontage road dipilih karena sudah tidak mungkin lagi dilakukan pelebaran jalan di Jalan Ahmad Yani terutama sisi timur karena ada Jalur Kereta Api. Sehingga solusi ini dianggap cara yang paling tepat yang bisa dilakukan untuk mengatasi kemacetan yang terjadi di persimpangan tersebut.

Kondisi simpang bersinyal pada Jalan Ahmad Yani Giant dengan adanya frontage road terlihat tetap bermasalah walaupun bukan pada jam sibuk. Masalah muncul ketika semua pengguna kendaraan mulai memenuhi ruas-ruas jalan pada saat jam puncak tertentu yaitu pagi, siang dan sore hari. Banyak kendaraan yang tertahan beberapa kali oleh lampu merah, khususnya pada Jalan Ahmad Yani Giant. Hal ini disebabkan karena banyaknya volume lalu lintas di kawasan tersebut. Untuk mengatasi masalah tersebut diperlukan adanya evaluasi kinerja simpang bersinyal dengan adanya frontage road agar menjadi lebih optimal.

Masalah naik turunnya penumpang kendaraan umum juga menjadi masalah pada persimpang tersebut. Dengan adanya frontage road yang mengurangi kepadatan dengan target masyarakat yang melewati jalan tersebut, diprediksi akan menimbulkan pengurangan lalu lintas yang dapat mengurangi beban jalan di sekitar lokasi.

Di Indonesia khususnya Surabaya menggunakan acuan Manual Kapasitas Jalan Indonesia. Manual Kapasitas Jalan Indonesia adalah suatu sistem yang disusun sebagai suatu metode efektif yang berfungsi untuk perancangan manajemen lalu lintas yang direncanakan terutama agar pengguna dapat memperkirakan perilaku lalu lintas dari suatu fasilitas pada kondisi lalu lintas geometrik dan keadaan lingkungan tertentu, sehingga diharapkan dapat membantu untuk mengatasi permasalahan kondisi lalu lintas di jalan perkotaan.

Simpang adalah suatu area yang kritis pada suatu jalan raya yang merupakan tempat titik konflik dan tempat kemacetan karena bertemunya dua ruas jalan atau lebih. Simpang yang dievaluasi adalah simpang bersinyal dimana simpang 
bersinyal merupakan suatu fasilitas jalan yang berlengan 3 atau 4 dengan bentuk geometrik serta menggunakan peralatan sinyal pengatur lalu lintas. Persimpangan Jalan Ahmad Yani Giant merupakan jalan arteri primer karena persimpangan ini menghubungkan kota Surabaya dengan kota-kota lain, seperti kota Sidoarjo, kecepatan kendaraan rata-rata tinggi, pergerakan lalu lintas menerus.

1. Kapan dipasang lampu lalu lintas?

Pada saat arus lalu lintas sudah mulai meninggi, maka lampu lalu lintas sudah harus dipasang. Ukuran meningginya arus lalu lintas yaitu dari waktu tunggu rata-rata kendaraam pada saat melintasi simpang. Jika waktu tunggu ratarata tanpa lampu lalu lintas sudah lebih besar dari waktu tunggu rata-rata dengan lampu lalu lintas, maka perlu dipasang lampu lalu lintas.

\section{Penentuan Fase}

Pada perencanaan lalu lintas, dikenal beberapa istilah :

a. Waktu silkus (cycle time) : waktu satu periode lampu lalu lintas, misalnya pada saat suatu arus diruas jalan A mulai hijau, hingga pada ruas jalan tersebut mulai hijau lagi.

b. Fase : suatu rangkaian dari kondisi yang diberlakukan untuk suatu arus atau beberapa arus, yang mendapatkan identifikasi lampu lalu lintas yang sama.

c. Bentuk Alih Gerak (manuver)

Dari sifat dan tujuan gerakan di daerah persimpangan, dikenal beberapa bentuk alih gerak (manuver) antara lain, diverging (memisah), merging (menggabung), crossing (memotong), dan weaving (menyilang).

1) Diverging (memisah)

Diverging adalah peristiwa memisahnya kendaraan dari suatu arus yang sama ke jalur yang lain:

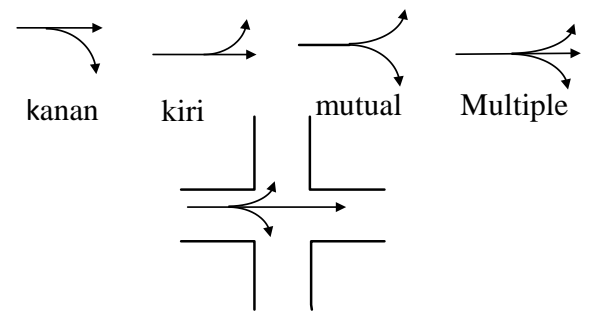

Gambar 1 Arus Diverging (memisah)

Sumber Munawar : $45-47$ 
2) Merging (menggabung)

Merging adalah peristiwa menggabungnya kendaraan dari suatu jalur ke jalur yang lain:

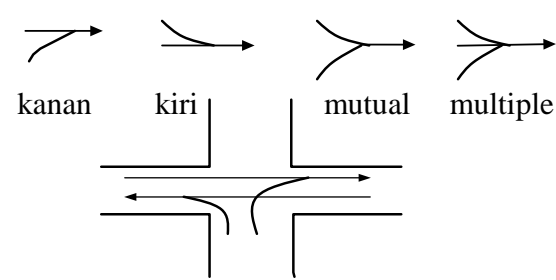

Gambar 2 Arus Merging (menggabung)

Sumber Munawar : $45-47$

3) Crossing (memotong)

Crossing adalah peristiwa perpotongan antara arus kendaraan dari satu jalur ke jalur yang lain pada persimpangan di mana keadaan yang demikian akan menimbulkan titik konflik pada persimpangan tersebut.

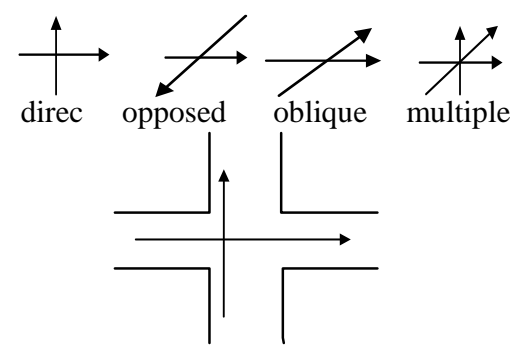

Gambar 3 Arus Crossing (memotong)

Sumber Munawar : $45-47$

4) Weaving (menyilang)

Weaving adalah pertemuan dua arus lalu lintas atau lebih yang berjalan menurut arah yang sama sepanjang suatu lintasan di jalan raya tanpa bantuan rambu lalu lintas. Gerakan ini sering terjadi pada suatu kendaraan yang berpindah dari suatu jalur ke jalur lain misalnya pada saat kendaraan masuk ke suatu jalan raya dari jalan masuk, kemudian bergerak ke jalur lainnya untuk mengambil jalan keluar dari jalan raya tersebut keadaan ini juga akan menimbulkan titik konflik pada persimpangan tersebut. 


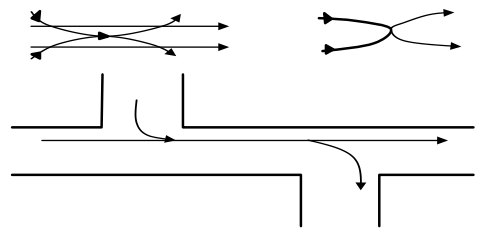

Gambar 4 Arus weaving (menyilang)

Sumber Munawar : $45-47$

Frontage road adalah jalan pendamping jalan utama yang menyediakan akses ke jalan masuk pribadi seperti pusat perbelanjaan, industri, kantor, dll. Frontage road memberikan alternatif rute untuk mengurangi kemacetan di jalan utama sehingga diahlihkan ke frontage.

\section{Pengenalan Teori Graf}

Teori graf adalah cabang ilmu yang mempelajari sifat-sifat graf, yang pertama kali diperkenalkan pada tahun 1736. Baru pada sekitar tahun 1920 teori graf berkembang pesat terutama salah satunya adalah aplikasinya yang sangat luas dalam kehidupan sehari-hari maupun dalam berbagai bidang ilmu seperti: Ilmu Komputer, Teknik, Sains, bahkan Ilmu Sosial. (Ketut, 2007 : 1).

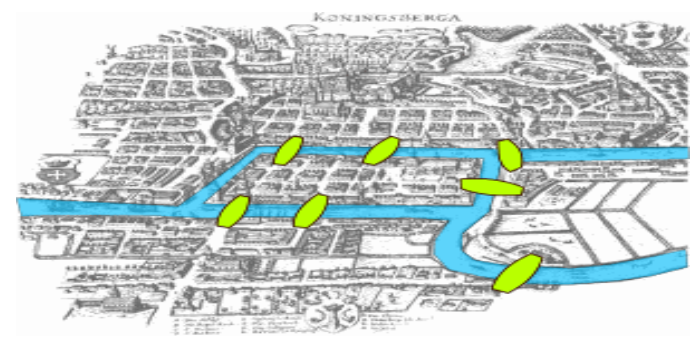

Gambar 5 Jembatan utama di Königsberg Sumber Munir : 355

Menurut catatan sejarah, masalah jembatan Königsberg adalah masalah yang pertama kali menggunakan graf tahun 1739 (Munir, 2005 : 354). Di kota Königsberg (sebelah timur negara bagian Prussia, Jerman), sekarang bernama kota Kaliningrad, terdapat sungai Pregal yang mengalir mengitari pulau Kneiphof lalu bercabang menjadi dua buah anak sungai yang diperlihatkan oleh gambar 2.5. Permasalahannya ialah menemukan pejalanan atau rute dari suatu kota melalui ketujuh buah jembatan masing-masing tepat satu kali, kemudian kembali lagi ke tempat awal. Pulau tersebut tidak dapat dicapai oleh rute apapun selain melalui jembatan-jembatan tersebut. 


\section{Pengaturan Lampu Lalu Lintas Di Persimpangan Jalan Ahmad Yani Giant Dengan Aplikasi Pewarnaan Teori Graf}

\section{Definisi Graf}

Graf $G$ didefinisikan sebagai pasangan himpunan $(V, E)$, ditulis dengan notasi $G=(V, E)$ (Munir, 2005 : 356). Sebuah graf $G$ berisikan dua himpunan yaitu himpunan berhingga tak kosong $V(G)$ dari objek-objek yang disebut titik dan himpunan berhingga (mungkin kosong) $E(G)$ yang elemen-elemennya disebut sisi sedemikian hingga setiap elemen $e$ dalam $E(G)$ merupakan pasangan tak berurutan dari titik-titik di $V(G)$ disebut himpunan titik $G$ dan $E(G)$ disebut himpunan sisi G (Ketut, 2007 : 2).

Menurut Munir (2005: 356), graf $G$ didefinisikan sebagai pasangan himpunan $(V, E)$, ditulis dengan notasi $G=(V, E)$, yang dalam hal ini $V$ adalah himpunan tidak kosong dari titik-titik (vertices atau node) dan $E$ adalah himpunan sisi (edges atau arcs) yang menghubungkan sepasang titik, $E$ boleh kosong. Jadi, sebuah graf dimungkinkan tidak mempunyai sisi, tetapi titiknya harus ada minimal satu. Graf yang hanya mempunyai satu buah titik tanpa sisi dinamakan graf trivial.

\section{Pewarnaan pada Graf}

1. Algoritma pewarnaan graf (Welch - Powell) :

Inputnya dalah suatu graf $G$

Langkah 1 : Urutkan verteks $G$ menurut derajat yang mengecil.

Langkah 2: Biarkan warna pertama $C_{1}$ pada verteks pertama dan lalu, secara berurutan, berikan $C_{1}$ ke setiap verteks yang tidak bersebelahan dengan verteks sebelumnya yang telah diberi $C_{l}$.

Langkah 3 : Ulangi langkah 2 dengan warna kedua $C_{2}$ dan verteks berikutnya yang belum diwarnai.

Langkah 4: Ulangi Langkah 3 dengan warna ketiga $C_{3}$, lalu warna keempat $C_{4}$, dan demikian seterusnya sampai semua verteks telah diwarnai.

Langkah 5 : Keluar

Microsoft Visual Basic 6.0 merupakan bahasa pemrograman yang cukup populer dan mudah untuk dipelajari serta dapat membuat program dengan aplikasi GUI (Graphical User Interface) atau program yang memungkinkan pemakai 
komputer berkomunikasi dengan komputer tersebut dengan menggunakan modus grafik atau gambar (Hardianti, 2013: 35).

Visual Basic adalah salah satu development tool untuk membangun aplikasi dalam lingkungan windows. Dalam pengembangan aplikasi, visual basic menggunakan pendekatan visual untuk merancang user intervace dalam bentuk form, sedangkan untuk kodingnya menggunakan pendekatan bahasa basic. Basic telah menjadi tools yang terkenal bagi para pemula maupun para developer dalam pengembangan aplikasi skala kecil sampai ke skala besar. Dalam lingkungan Window's User-interface sangat memegang peranan penting, karena dalam pemakaian aplikasi yang kita buat, pemakai senantiasa berinteraksi dengan user interface tanpa menyadari bahwa dibelakangnya berjalan instruksi-instruksi program yang mendukung tampilan dan proses yang dilakukan.

\section{METODE PENELITIAN}

Data primer, yaitu data yang diperoleh dengan pengamatan langsung dan pencatatan secara langsung dari tempat penelitian, yaitu pada lampu lalu lintas di persimpangan simpang tiga jalan Ahmad Yani Giant, Kota Surabaya. Data sekunder adalah data penunjang yang diperoleh melalui dokumen, buku, maupun instansi atau lembaga yang mempunyai data yang relevan, dalam penelitian ini yaitu Dinas Perhubungan Kota Surabaya.

Penelitian dilakukan di persimpangan simpang tiga jalan Ahmad Yani Giant, Kota Surabaya. Bagian yang diamati adalah berapa waktu tunggu pada lampu lalu lintas. Waktu penelitian dilakukan pada pagi, siang, dan sore.

Metode yang digunakan dalam penelitian ini adalah metode observasi yang merupakan metode pengumpulan data dengan cara pengamatan atau peninjauan langsung terhadap objek penelitian. yang sama untuk dipilih.

Data pada penelitian ini diperoleh dengan mengamati jumlah waktu pada persimpangan simpang tiga jalan Ahmad Yani Giant, secara langsung.

\section{HASIL PENELITIAN DAN PEMBAHASAN}

Langkah pertama adalah menentukan lokasi penelitian. Penelitian akan dilaksanakan di persimpangan jalan Ahmad Yani Giant. Pada penelitian ini, dibuat 
penerapan pewarnaan graf untuk menentukan arus lampu lalu lintas yang menggambarkan keadaan dengan objek penelitian, yaitu persimpangan jalan Ahmad Yani Giant, Surabaya. Selanjutnya gambar persimpangan tersebut diubah ke bentuk graf atau dibuat subgraf, kemudian dilakukan proses pengaturan arah arus yang dapat berjalan secara bersamaan dengan aman dan konsisten berdasarkan waktu tunggu tiap jalur.

1. Waktu pengambilan data akan dibagi pada tiga periode waktu, yaitu:

a. Pagi hari, dibatasi pada pukul 06.30-07.30 WIB, dengan asumsi banyaknya pekerja dan pelajar yang berangkat pada jam tersebut.

b. Siang hari, dibatasi pada pukul 12.30-13.30 WIB, dengan asumsi banyaknya pelajar yang pulang dan aktivitas lain pada jam tersebut.

c. Sore hari, dibatasi pada pukul 16.30-17.30 WIB, dengan asumsi banyaknya pekerja yang pulang.

2. Data yang diamati pada tiap ruas jalan dari dua arah hanya kendaraan bermotor dan roda empat, sedangkan pejalan kaki dan penyeberang jalan diabaikan.

\section{Gambar Sistem Arus Lalu Lintas}

Jika akan menggambar arus lalu lintas perlu melakukan observasi awal untuk menentukan banyaknya lintasan yang diperbolehkan melintas pada persimpangan tersebut dan untuk menentukan lintasan mana saja yang diperbolehkan melintas. Berdasarkan pengamatan yang dilakukan di lapangan, sistem lalu lintas yang diterapkan pada persimpangan jalan dapat dilihat pada gambar 6 .

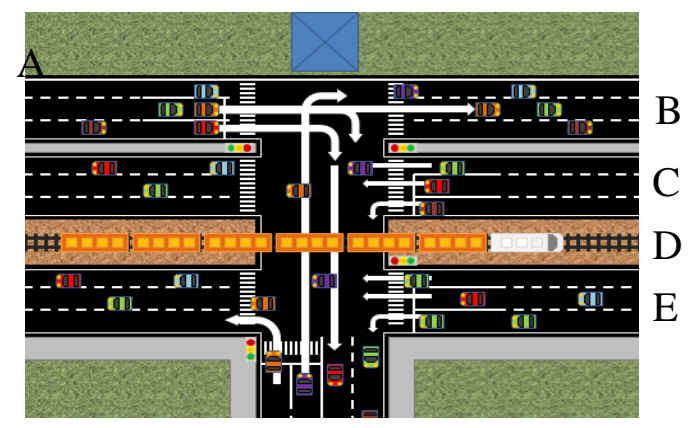

$\mathrm{F}$

Gambar 6 Ilustrasi Arus Lalu Lintas di Persimpangan Tiga Jalan Ahmad Yani Giant

Keterangan Gambar :

A : Kantor Pos Polisi

B : Jalan Ahmad Yani Arah Utara

C : Jalan Ahmad Yani Arah Selatan 
D : Perlintasan Kereta Api

E : Jalan frontage Ahmad Yani

F : Jalan Margorejo

Pada Gambar 6 di atas terdapat beberapa lintasan, yaitu:

B : Dari Sidoarjo ke Arah Jalan Ahmad Yani Utara

BF : Arah Sidoarjo ke Jalan Margorejo

C : Arah Jalan Ahmad Selatan Yani ke Sidoarjo

CF : Arah Ahmad Yani Selatan ke Jalan Margorejo

E : Arah Frontage Jalan Ahmad Yani Selatan ke Sidoarjo

FE : Arah Margorejo ke Jalan Frontage Ahmad Yani Selatan

Berikut akan dipaparkan penyelesaian kasus pengaturan lampu lalu lintas pada persimpangan jalan Ahmad Yani Giant.



Gambar 7 Ilustrasi arus uncompatible (tidak boleh berjalan bersamaan) simpang jalan Ahmad Yani Gaint

Arus-arus yang uncompatible (tidak boleh berjalan bersamaan) adalah :

a. Arus $v_{2}$ tidak boleh berjalan bersamaan dengan $v_{3}, v_{5}, v_{7}$

b. Arus $v_{3}$ tidak boleh berjalan bersamaan dengan $v_{2}, v_{7}$

c. Arus $v_{4}$ tidak boleh berjalan bersamaan dengan $v_{5}$

d. Arus $v_{5}$ tidak boleh berjalan bersamaan dengan $v_{2}, v_{4}, v_{7}$

e. Arus $v_{7}$ tidak boleh berjalan bersamaan dengan $v_{2}, v_{3}, v_{5}$

Keterangan :

1) $v_{1}$ : Dari Sidoarjo ke arah Ahmad Yani Utara

2) $v_{2}$ : Dari Sidoarjo ke arah Margorejo

3) $v_{3}$ : Dari arah Ahmad Yani Utara ke Sidoarjo

4) $v_{4}$ : Dari arah Ahmad Yani Utara ke Margorejo

5) $v_{5}$ : Dari arah frontage Ahmad Yani Utara ke Sidoarjo

6) $v_{6}$ : Dari arah frontage Ahmad Yani Utara ke Margorejo

7) $v_{7}$ : Dari arah Margorejo ke arah Ahmad Yani Utara

8) $v_{s}$ : Dari arah Margorejo ke arah Sidoarjo 


\section{Pewarnaan Pada Graf}

Tabel 8 Data sekunder persimpangan jalan Ahmad Yani Giant

\begin{tabular}{|l|l|l|l|l|}
\hline Kaki Simpang & Utara & Selatan & Timur & Total \\
\hline Merah & 46 & 42 & 46 & 134 \\
\hline Hijau & 18 & 22 & 18 & 58 \\
\hline Total & 64 & 64 & 64 & 192 \\
\hline
\end{tabular}

Langkah-langkah penyelesaian perhitungan lampu lalu lintas di persimpangan jalan Ahmad Yani Giant sebagai berikut :

a) Mentransformasi persimpangan jalan Ahmad Yani Giant ke dalam bentuk graf sebagai berikut :

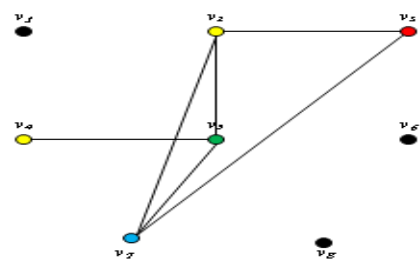

Gambar 9 Pewarnaan Graf persimpangan jalan Ahmad Yani Giant

Dari transformasi graf diatas diketahui titik $v_{1}, v_{6}$, dan $v_{8}$ merupakan titik asing yaitu titik yang tidak saling terhubung dengan titik lain. Sehingga arus yang dinyatakan dengan titik $v_{1}, v_{6}$, dan $v_{8}$ dapat berlangsung beriringan dengan arus lain atau dapat berlaku terus lampu hijau.

b) Mewarnai graf dengan algoritma Welch-Powell untuk mencari bilangan khromatik. Dengan menggunakan algoritma Welch-Powell dihasilkan pewarnaan graf sebagai berikut :



Gambar 10 Hasil pewarnaan graf pada persimpangan jalan Ahmad Yani Giant

Dari pewarnaan graf di atas diperoleh bilangan khromatik $=3$. Untuk kasus pada persimpangan jalan Ahmad Yani Giant, titik $v_{4}$ tidak saling adjacent dengan titik $v_{3}, v_{6}$, dan $v_{8}$ sehingga warna titik $v_{4}$ bisa diseragamkan dengan 


\section{Erna Lus Diana', Wahyuni Suryaningtyas ${ }^{2}$, Endang Suprapti ${ }^{3}$}

titik $v_{2}$. Hal ini akan berpengaruh pada penyelesaian arus yang dapat berjalan secara bersamaan. Penyelesaian arua-arus yang dapat berjalan bersamaan disajikan dalam Tabel 11 berikut.

\begin{tabular}{|c|c|}
\hline Warna & Titik \\
\hline Kuning & $v_{2}, v_{4}$ \\
\hline Hijau & $v_{3}, v_{5}$ \\
\hline Merah & $v_{7}$ \\
\hline
\end{tabular}

Tabel 11 Warna titik graf pada persimpangan jalan Ahmad Yani Giant

Dari Tabel 11 di atas dapat dibuat 3 partisi pangaturan lampu lalu lintas, dimana pada partisi pertama, arus $v_{2}$ berjalan bersama arus $v_{4}$, pada partisi kedua arus $v_{3}$ berjalan bersama arus $v_{5}$, dan pada partisi ketiga arus $v_{7}$ akan berjalan sendiri.

c) Menentukan alternatif penyelesaian durasi lampu merah dan hijau menyala.

Berdasarkan data sekunder, durasi waktu satu siklus 64 detik, setelah dilakukan pembagian dengan bilangan khromatik $=3$, diperoleh durasi lampu hijau menyala yaitu 21.33 detik dan lampu merah menyala yaitu 42.67 detik. Namun untuk $v_{1}$ yang dapat berjalan bersamaan dengan $v_{6}$ dan $v_{8}$ maka durasi lampu hijau akan bertambah menjadi 42.67 detik dan durasi lampu merah menyala berkurang menjadi 21.33 detik.

Selanjutnya, data baru durasi lampu merah dan hijau untuk lampu lalu lintas pada persimpangan jalan Ahmad Yani Giant pada table 4.12.

Tabel 12 Penyelesaian lampu lalu lintas pada arus persimpangan jalan Ahmad Yani Giant

\begin{tabular}{|l|l|c|c|c|c|c|c|l|}
\hline Titik & $v_{1}$ & $v_{2}$ & $v_{3}$ & $v_{4}$ & $v_{5}$ & $v_{6}$ & $v_{7}$ & $v_{8}$ \\
\hline Merah & 0 & 42.67 & 21.33 & 42.67 & 21.33 & 0 & 42.67 & 0 \\
\hline Hijau & 64 & 21.33 & 42.67 & 21.33 & 42.67 & 64 & 21.33 & 64 \\
\hline
\end{tabular}

Tabel 13 Data baru lampu lalu lintas pada persimpangan jalan Ahmad Yani Giant

\begin{tabular}{|l|l|l|l|l|}
\hline $\begin{array}{l}\text { Kaki } \\
\text { Simpang }\end{array}$ & Utara & Selatan & Timur & Total \\
\hline Merah & 42.67 & 42.67 & 21.33 & 106.67 \\
\hline Hijau & 21.33 & 21.33 & 42.67 & 85.33 \\
\hline Total & 64 & 64 & 64 & 192 \\
\hline
\end{tabular}




\section{Pengaturan Lampu Lalu Lintas Di Persimpangan Jalan Ahmad Yani Giant Dengan Aplikasi Pewarnaan Teori Graf}

Berdasarkan durasi lampu merah dan hijau menyala pada persimpangan jalan Ahmad Yani Giant dapat diketahui bahwa data hasil penyelesaian pewarnaan titik dengan algoritma Welch-Powell lebih efektif dari pada data sekunder dari Dinas Perhubungan Kota Surabaya tahun 2015. Berikut disajikan table data sekunder dan data baru.

\begin{tabular}{|l|l|l|l|l|}
\hline \multirow{2}{*}{$\begin{array}{c}\text { Kaki } \\
\text { Simpang }\end{array}$} & \multicolumn{2}{|c|}{ Data Sekunder } & \multicolumn{2}{c|}{ Data Baru } \\
\cline { 2 - 5 } & Merah & Hijau & Merah & Hijau \\
\hline Utara & 46 & 18 & 42.67 & 21.33 \\
\hline Selatan & 42 & 22 & 42.67 & 21.33 \\
\hline Timur & 46 & 18 & 21.33 & 42.67 \\
\hline Total & 134 & 58 & 106.67 & 85.33 \\
\hline
\end{tabular}

Tabel 14 Data sekunder dan data baru lampu lalu lintas persimpangan jalan Ahmad Yani Giant

Durasi total lampu merah menyala dari data sekunder adalah 134 detik, sedangkan dengan pewarnaan titik durasi total lampu merah menyala adalah 106.67detik. Tingkat efektifitasnya yaitu :

$\frac{\text { Merah Baru - Merah Lama }}{\text { Merah Lama }} \times 100 \%$

$=\frac{134-106.67}{106.67} \times 100 \%$

$=\frac{27.33}{106.67} \times 100 \%$

$=25.62 \%$

Durasi total lampu hijau menyala dari data sekunder adalah 58 detik, sedangkan dengan pewarnaan titik durasi total lampu hijau menyala adalah 85.33 detik. Tingkat efektifitasnya yaitu :

$\frac{\text { Hijau Baru - Hijau Lama }}{\text { Hijau Lama }} \times 100 \%$

$=\frac{85.33-58}{58} \times 100 \%$

$=\frac{27.33}{58} \times 100 \%$

$=47.12 \%$ 
Jadi, untuk kasus lampu lalu lintas persimpangan jalan Ahmad Yani Giant durasi lampu merah menyala akan menurun sebesar $25.62 \%$, sedangkan durasi lampu hijau menyala akan meningkat sebesar $47.12 \%$.

\section{SIMPULAN}

1. Pewarnaan simpul dengan algoritma Welch-Powell dapat diapliasikan untuk menyelesaikan perhitungan durasi waktu pada lampu lalu lintas. Langkah yang ditempuh yaitu dengan mentransformasikan persimpangan jalan beserta arusnya ke dalam bentuk graf. Simpul merepresentasikan arus dan garis merepresentasikan arus yang uncompatible. Selanjtunya mewarnai simpul pada graf dengan algoritma Welch-Powell untuk mengetahui arus yang dapat berjalan bersamaan dengan memperoleh bilangan khromatik yang berfungsi untuk menentukan alternatif penyelesaian durasi waktu lampu lalu lintas. Berdasarkan durasi lampu merah dan lampu hijau pada persimpangan jalan Ahmad Yani Giant dapat diketahui bahwa data baru hasil penyelesaian pewarnaan simpul dengan algoritma Welch-Powell lebih efektif daripada data sekunder dari Dinas Perhubungan Kota Surabaya.

2. Berdasarkan hasil penelitian didapat bentuk graf pemodelan arus lalu lintas pada persimpangan jalan Ahmad Yani Giant.

a. Bentuk graf pada persimpangan jalan Ahmad Yani - Giant.

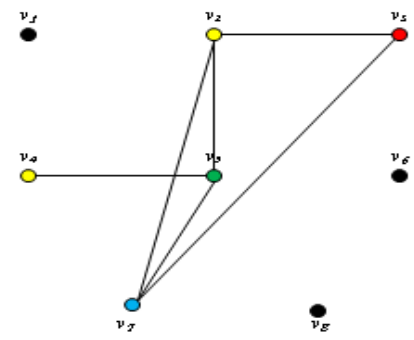

b. Mewarnai graf dengan algoritma Welch-Powell untuk mencari bilangan khromatik. Dengan menggunakan algoritma Welch-Powell dihasilkan pewarnaan graf sebagai berikut :

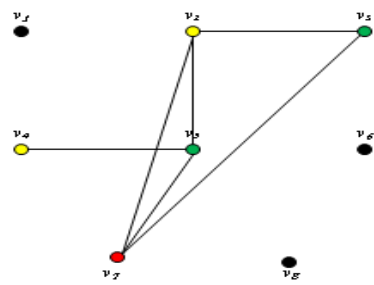




\section{Pengaturan Lampu Lalu Lintas Di Persimpangan Jalan Ahmad Yani Giant Dengan Aplikasi Pewarnaan Teori Graf}

Dari pewarnaan graf di atas diperoleh bilangan khromatik $=3$. Untuk kasus pada persimpangan jalan Ahmad Yani Giant, titik $v_{4}$ tidak saling adjacent dengan titik $v_{3}, v_{6}$, dan $v_{8}$ sehingga warna titik $v_{4}$ bisa diseragamkan dengan titik $v_{2}$. Hal ini akan berpengaruh pada penyelesaian arus yang dapat berjalan secara bersamaan.

Tabel 5.1 Warna titik graf pada persimpangan jalan Ahmad Yani - Giant

\begin{tabular}{|c|c|}
\hline Warna & Titik \\
\hline Kuning & $v_{2}, v_{4}$ \\
\hline Hijau & $v_{3}, v_{5}$ \\
\hline Merah & $v_{7}$ \\
\hline
\end{tabular}

Dari Tabel 5.1 di atas dapat dibuat 3 partisi pangaturan lampu lalu lintas, dimana pada partisi pertama, arus $v_{2}$ berjalan bersama arus $v_{4}$, pada partisi kedua arus $v_{3}$ berjalan bersama arus $v_{5}$, dan pada partisi ketiga arus $v_{7}$ akan berjalan sendiri.

c. Menentukan alternatif penyelesaian durasi lampu merah, kuning, dan hijau menyala.

Berdasarkan data sekunder, durasi waktu satu siklus 64 detik, setelah dilakukan pembagian dengan bilangan khromatik =3, diperoleh durasi lampu hijau menyala yaitu 21.33 detik, durasi lampu kuning meyala yaitu 3 detik dan lampu merah menyala yaitu 42.67 detik. Namun untuk $v_{1}$ yang dapat berjalan bersamaan dengan $v_{\sigma}$ dan $v_{\mathcal{B}}$ maka durasi lampu hijau akan bertambah menjadi 42.67 detik dan durasi lampu merah menyala berkurang menjadi 21.33 detik.

3. Dengan menerapkan program Visual Basic pada pengaturan lampu lalu lintas diperoleh hasil bahwanya sistem tersebut efektif apabila tidak ada penumpukan atau antrian kendaraan dengan kapasitas yang berlebihan. Apabila penumpukan atau antrian kendaraan dengan kapasitas berlebihan maka sistem tersebut tidak efektif sehingga cara yang digunakan adalah cara manual, dengan sistem petugas harus mengatur lampu lalu lintas secara manual dilihat pada kamera CCTV yang terpasang pada lampu lalu lintas dan polisi lalu yang bertugas ditempat kejadian. 
Diharapkan dapat mengurangi resiko kemacetan, kecelakaan, atau gangguan lain yang dapat terjadi di jalan tersebut.

4. Kemacetan di Kota Surabaya disebabkan oleh semakin banyaknya atau bertambahnya volume kendaraan di setiap tahunnya yang sudah tidak seimbang dengan kapasitas jalan, kesadaran masyarakat untuk menggunakan transportasi umum juga masih kurang, hal ini disebabkan karena transportasi umum di kota Surabaya belum sepenuhnya memenuhi standar dan masih banyak yang tidak layak digunakan sehingga masyarakat lebih memilih menggunakan transportasi pribadi, banyak masyarakat yang tidak tertib berlalu lintas. Pemerintah harus membuat MRT supaya masyarakat lebih memilih menggunakan MRT dari pada menggunakan transportasi pribadi dan pemerintah juga harus menaikan tarif parkir di pusat perbelanjaan tengah kota, supaya masyarakat lebih menggunakan transportasi umum ketimbang transportasi pribadi.

\section{DAFTAR PUSTAKA}

Budayasa, I. K. 2007. Teori graf dan Aplikasinya. Surabaya :Unesa University Press.

Munir, R. 2012. Matematika Diskrit. Bandung: Informatika.

Wilson, R. J, \& Watkins, J. J. 1990. Graphs An Introductory Approach. Singapore: Johm Wiley \& sons, Inc.

Munawar, Ahmad. 2014. Manajemen Lalu Lintas Perkotaan. Yogyakarta: Beta Offset.

Manik, N. I. 2014. Matematika Diskrit Soal-Jawab. Yogyakarta: Graha Ilmu.

Enterprise, Jubilee. 2015. Trik Membuat Skripsi \& Statistik Dengan Word dan SPSS. Jakarta: PT Elex Media Komputindo.

Lee, Christopher. 2014. Buku Pintar Pemrograman Visual Basic 2010. Jakarta: PT Elex Media Komputindo.

Balakrishnan, V. K. 1997. Schaum's Outlines Graph Teory. USA: The McGrawHill Companie, Inc.

Deo, Narsingh. 1974. Graph Theory with Applications to Engineering and Computer Science. USA: Prentice-Hall, Inc.

Balakrihnan, R, \& Ranganathan, K. 2012. A Textbook of Graph Theory. New York: Springer.

Gross, J. L, Yellen, J, Zhang, P. 2014. Handbook of Graph Theory. New York: CRC Press.

Lipshutz, S, \& Lipson, M. 2007. Schaum's Outlines Discrete Mathematics. USA: The McGraw-Hill Companie, Inc.

Rachmawati, C \& Novitasari, D. T. 2013. Evaluasi Kinerja Lalu Lintas Simpang Bersinyal Jl. A. Yani-Jl. Margorejo dengan Adanya Frontage Road Surabaya. Surabaya: Diploma II Teknik Sipil ITS. 
http://dishub.surabaya.go.id/ diakses pada tgl 10 Juli 2015 pukul 19.38

Itsnaini, Nurul. 2013. Meningkatkan Hasil Belajar Matematika Siswa Kelas VII C SMP Negeri 1 Sampang Melalui Model Pembelajaran Kooperatif Tipe Make A Match. Surabaya: Universitas Muhammadiyah Surabaya.

Wilujeng, N. R. 2013. Pembelajaran Kooperatif Dengan Pendekatan V Air Pada Materi Segiempat Siswa Kelas VII SMP Islam Al-Azhar Kelapa Gading Surabaya. Surabaya: Universitas Muhammadiyah Surabaya. 